\title{
Study on Strategies of Basketball Game in Basketball Teaching
}

Fei Liu

University of Electronic Science and Technology of China, Chengdu, Sichuan, 611731

Keywords: Basketball, Basketball Teaching, Basketball Game Teaching, Strategy.

\begin{abstract}
The daily basketball sports teaching process, there are a variety of basketball teaching methods, different teachers of basketball teaching methods are different. In recent years, basketball teaching in the use of basketball games more and more, a lot of basketball teachers are students to take basketball game teaching methods, in order to improve the level of basketball students. This article mainly on the basketball teaching basketball game teaching strategy to study, grasp the teaching characteristics of basketball games.
\end{abstract}

\section{Introduction}

The training period is an important period of basketball students' thinking, just as IQ and physical development period, as for basketball thinking exercise and shaping in the training period is the most effective. Daily basketball teaching, there are a variety of basketball teaching methods, different teachers of basketball teaching methods are different. Therefore, in the training process, should be basketball awareness in the first place, and actively guide students to basketball thinking and basketball awareness, so that the future development of basketball students has a great help. At this stage, the teaching of basketball is in the application of basketball games more and more teaching methods, many basketball teachers are students to take basketball game teaching methods, in order to improve the level of basketball students.

\section{The Student's Basketball Game Teaching}

Ordinary basketball training, the use of basketball game teaching methods to enable students to relax nerves to relax, to ease the tension of students, to avoid the occurrence of radical training, resulting in damage to the students' bodies, to ensure that students in the basketball training in the best status. In recent years, the way of basketball game teaching by everyone's pursuit, the purpose of this teaching is to allow students in the daily basketball game training to relax the state to face, so all-round to improve their own basketball skills. Basketball game teaching is the main form of basketball as the center of the expansion of the game, which in the game to be trained in the training to relax, such as dribble to catch up, multiplayer and other games, the daily training and game Together, in order to make basketball game teaching to achieve the dual purpose of teaching and training. So that basketball students in this teaching way to relax, threw himself into the game training, this can help students will not be too nervous, and cause physical damage.

First of all, this teaching method for the teacher, there is a certain guiding role, the teacher in the practice of practice there are many conceptual problems. From the cognitive level, this teaching method can not only change the concept of teachers, establish a correct concept of human basketball sports, but also to further improve the understanding of basketball itself, enrich the content of basketball teaching.

Secondly, the development of basketball students, basketball game teaching for students to create a self-development and perfect environment, not only to highlight the student's dominant position, concerned about the health of students, to meet the reasonable needs of students, to fully To mobilize the enthusiasm and initiative of student training, to maximize the development of the potential of students, but also help to improve students' awareness of basketball, change the 
traditional concept of basketball sports, and promote the comprehensive and coordinated development of students.

Finally, from the development needs of basketball, Chinese basketball is to carry out quality education. But this type of education is often not achieved through training, but to create a positive and healthy basketball atmosphere. This positive and healthy basketball atmosphere, for students, has a very important influence, can help them better training.

\section{The role of basketball game teaching}

Help to mobilize the enthusiasm and initiative of students. For the repeated training of basketball, a single routine training will make students have a sense of fatigue, resulting in a substantial decline in the quality of training. Through the teaching of basketball games, students can naturally experience the fun of basketball, can improve the excitement and initiative of students in the basketball game teaching, students do not have to follow the complex rules, you can experience in basketball training To the joy of the game, so that they can long to maintain the desire for the exploration of basketball, so as to better achieve the purpose of teaching.

Basketball is a very simple start to learn, but to improve the technical skills of basketball more difficult sports, but through the basketball game teaching methods to enable students in the entertainment atmosphere, to master the technical master, such as in the daily training, Always throw no three-pointers, then the process of basketball games, students relax their own mentality, according to the basis of previous training, it will easily throw into the three-pointers.

Basketball teaching methods can improve the sensitivity of students' actions and physical confrontation, basketball game is relatively complex, the need for students to good physical fitness, basketball game is a very test of students, so for students, the basketball game The ability to exercise students' thinking has a very important role in the student's agility and stability, and these abilities require the students to have.

Basketball is a team fighting campaign, so it requires students to have a full understanding between, to have a team spirit, basketball game teaching methods help to cultivate the unity and understanding between students in the course of the game, training The team spirit of the students, so that later in the basketball training to better allocation of tasks.

\section{The use of basketball game teaching principles}

In sports, security has become the most important issue, in the use of basketball game teaching methods, pay attention to the safety of students in the first place. In the fight against the competitive and competitive basketball game, students are often running, dodge and chase the state, in the basketball game, the students are often in a state of extreme excitement, and basketball put a hundred percent attention, Making students prone to collision with each other, sprain, slipping and so on. Therefore, in the basketball game teaching, the safety of the action and operability is to assess, to ensure that students' personal safety. In addition, the teacher and students to emphasize the essentials of the action and the rules of the game, to strengthen the safety of students education, the venue should be a reasonable arrangement and design, pay attention to the placement of sports equipment, prevention and control of students in the game collision, to prevent the occurrence of accidents The

Arrange basketball games, not only to pay attention to the rules of the game itself, methods and fun, but also to consider the students' physical fitness, psychological characteristics, gender and age and other factors, according to the different students to develop a different reasonable game teaching program. Students in the game only to bear a certain physical and psychological load in order to have a corresponding training effect, large load of the amount of exercise or too small load not only can not achieve good teaching results, and even the students Physical and mental health hazards. So, every time a teacher designs a basketball game, he should control the amount of exercise in just the right range, so that when the students bring challenges at the same time, they do not exceed their greatest ability to withstand the phenomenon of excessive fatigue, so as to 
Influence the teaching quality of basketball.

Basketball game is a conscious sport, the impact of different games on the students to participate is not the same. Basketball games can not only be used to increase the student's relaxation while influencing basketball skills. Its content in the selection and use of both have a clear targeted. In order to achieve good results in the teaching of basketball lessons, to better complete the teaching tasks, it is necessary to basketball content and basketball teaching tasks and content combined. For example: the main purpose of basketball teaching is to enable students to master the skills of dribbling, then in this case, you can choose "dribble catcher" and "curve dribbling relay" and other games to train students to make In the game skilled to master the technology. In addition, it should be noted that some of the technical methods of basketball can not be reluctantly combined with the game, this may lead to technical action is not standardized, the standard will make the game lost the original fun.

\section{The specific application of basketball game teaching}

Basketball technical teaching is one of the core content of basketball teaching, in the teaching of teaching the use of basketball game teaching methods have the following requirements:

First, in the beginning to teach basketball technology should not be taught through the game. In the initial stage of the technical action of the students, the teacher should fully play the leading role, through the simple explanation of the basic knowledge and demonstration of the correct action, in the teaching process to highlight the action points, but also through repeated Practice so that students understand the basic movements, and master the basic structure of action. If at this time the use of basketball games to assist teaching, the results tend to be counterproductive. Because in the initial stage, the students for the basketball technology action unfamiliar, stiff, the body is not coordinated, the excess action more, it is easy to interfere with other actions, the use of basketball game teaching not only can not concentrate on learning activities, By the interference caused by the game, hinder the students of the action of the formation of the normative technology.

Second, in the consolidation of basketball skills to consolidate the stage, should be scientific and careful use of basketball games. With the continuous learning of basketball technology, students of the technical action has been the initial shape, but the students' movements and technology is not stable enough, when the fresh stimulus occurs when the action will lead to easy deformation. This time, you can properly use some of the relevant basketball games to consolidate the action and technology, but the outcome of the game to determine the accuracy and norms. For example: in the "free throw even" game, the provisions of a continuous penalty two ball a point, first get the fifth of the party to win. In this game, students will pay attention to the quality of shooting and throwing, in order to improve the basketball hit rate, in this way, in basketball teaching to achieve significant teaching results. On the contrary, for example: "free throw more than" this game, provided in a certain period of time, free throws scored more than one party to win. The application of this game increases the speed of the student's shot so that the total number of shots can be increased in a limited amount of time to increase the number of hits, and the result of this method is to make the students anxious to speed up the pitch while in the game Shooting action.

Third, the student's action has reached the stage of automation, the teacher to choose some confrontational and comprehensive game. In the student's technical action has been formed when the degree of automation reached, the teacher should increase the difficulty of basketball games. For example, in the teaching of basketball dribbling for students, students have the ability to protect the ball while dribbling, and the ability to use basketball skills in confrontation with each other after mastering the basic essentials of action. Choose "protect your own ball, grab someone else's ball" in this game, in the game of competition and confrontation, to consolidate the skills to improve students to learn.

In basketball teaching, basketball technology teaching is the most difficult and most important, in this process, not only to cultivate the team spirit of the students, so that they can cooperate in the basketball, co-operation, but also to allow students to Tactical implementation to play their own subjective initiative, in a reasonable premise, their own offensive and defensive action. On the one 
hand, in the case of a simple tactical cooperation, you can train the way through the basketball game training. For example: "man-to-man defense game", the game requires two teams equal to each team, each team has 5 - 6 students in the entire basketball court offensive and defensive game. Defensive players based on a reasonable division of the situation to find their opponents, attackers can not dribble in addition to the rest of the rest are based on the rules of the basketball competition. Through this game, people who help defend the defender have the ability to tighten opponents, improve the ability to interfere with the passing and capping shots, as well as practice in accordance with the location of the ball reasonable position in order to be able to and their own players to carry out defense The On the other hand, in the case of complex basketball tactics, not suitable for the use of basketball game teaching. Basketball tactics include many elements, with more complex features, it has a variety of organizational forms, the scope of competition for different sizes. These factors can not be embodied in a basketball game, the actual training, there is no suitable basketball game can play an effective training.

\section{Conclusion}

Basketball game teaching this way of comprehensive, systematic and diverse for basketball students, is undoubtedly the most suitable for basketball training. But to consider the differences between individuals, some basketball students are not very fit in basketball game teaching this way. Therefore, the teacher is in the process of basketball teaching, the traditional training methods and basketball game teaching methods to develop a suitable training for basketball students, in order to enhance the training of basketball students and professional level. In addition, basketball game teaching can help students to reduce the pressure to adjust their state of tension, to ensure that basketball training has a multiplier effect.

\section{References}

[1] Zhao Rubin.Experimental study on the effect of basketball game teaching on the basketball teaching effect of the second senior middle school in Luannan County, Tangshan City [D]. Tianjin Institute of Physical Education, 2014

[2] Zhao Feng. Analysis of the role of basketball games in basketball teaching and its use [J]. Sports Science and Technology, 2000, (04): 59-62. [2017-08-15].

[3] Peng Haisheng. Basketball teaching in the use of basketball game teaching strategy [J]. Contemporary sports science and technology, 2016,6 (03): $49+$ 51. (2016/4/13) [2017-08-15].

[4] Lei Huyi. Journal of Loulong Institute of Education, 2011, 28 (01): 111-113 + 115. [2017-08-15] [J]. Journal of Loulong Institute of Education, 2011, 28 (01): 111-113 + 115 [2017-08-15].

[5] Zhao Yunling. Basketball teaching in the use of basketball game teaching practice research [J]. Sports, 2014, (15): 79-80 +121. [2017-08-15]. 